\title{
The Effect of Television Decors on the Change of Reverberation Time of the Studio
}

\author{
Mohsen Karami, Masoumeh Shafieian \\ Department of Media Engineering, IRIB University, Tehran, Iran \\ Email: mohsenkarami.ir@gmail.com,shafieian@iust.ac.ir
}

Received January 1, 2013; revised February 2, 2013; accepted February 10, 2013

Copyright (C) 2013 Mohsen Karami, Masoumeh Shafieian. This is an open access article distributed under the Creative Commons Attribution License, which permits unrestricted use, distribution, and reproduction in any medium, provided the original work is properly cited.

\begin{abstract}
Reverberation time within studio's decor is changed because of addition of its surface to the overall surfaces of the studio and also the additional absorption of its materials. It seems reverberation time changes due to studio's decor is little because surface of the decor is small in comparison with the overall surfaces of the studio and surface has an important role in room constant and therefore in reverberation time. But these changes do not only depend on added surfaces and their absorption. Reverberation time is also dependent on shape of the decor and sometimes. It can decrease the effects of added surfaces which are used to increase the reverberation time. In this paper, a standard television studio is designed and implemented by using ODEON and 12 different decor which their dimensions and materials are similar to the actual ones, are applied inside the studio. Then studio's decor effects on reverberation time of the studio are computed, compared and analyzed.
\end{abstract}

Keywords: TV Studio; TV Decors; Reverberation Time; Coefficient of Absorption

\section{Introduction}

The time that is needed in order that the sound level from $60 \mathrm{~dB}$ above the threshold of hearing reach to the hearing level. This is the definition that was released by Sabin in 1895 and functions as an important factor in recognition of the acoustic property of the rooms yet. $\mathrm{RT}^{1}$ is one of most important factors in studying the quality of sound in studio and it has different amounts according to the size and its function. Reverberation time in one octave frequency bands is measured from $63 \mathrm{~Hz}$ to $8000 \mathrm{~Hz}$. The number that is given as the reverberation time of the room is actually the numerical average of reverberation time in frequencies of 500 and $1000 \mathrm{~Hz}$. This method is based on ISO3382 standard that has been considered in this essay. Two other factors can be extracted from reverberation time which shows the way of reverberation time in low and high frequencies and its ratio to reverberation time in intermediate frequency and therefore the warmth or sharpness of sound in environment. These parameters are BR and TR which are described with the Equation (1). RT is the reverberation time and its following number refers to its frequency $[1,2]$

\footnotetext{
${ }^{1}$ Reverberation time.
}

$\mathrm{BR}^{2}=\frac{\mathrm{RT} 125+\mathrm{RT} 500}{\mathrm{RT} 500+\mathrm{RT} 1000} \mathrm{TR}^{3}=\frac{\mathrm{RT} 1000+\mathrm{RT} 2000}{\mathrm{RT} 500+\mathrm{RT} 1000}(1)$

Researches on the effects of decors on sound are mainly about concert halls stages. Their goal was to provide better acoustic conditions for musicians and transmitting good sound to the audience. In 1976, Nakayama researched about reflective elements role in the stage and found out that these elements on ceiling and rear wall can preserve the acoustical conditions of the hall in the stage and this can enhance the sound homogeneity. He also pointed out that it is necessary to use reflective surfaces and strong diffusers on lateral, rear walls and if possible on ceiling [3]. In 2004, Kahle and Katz researches showed that to control absorption of sound energy it is needed to use absorption in stage decors and these absorbers are better to be on the rear wall. They don't mention absorber material and its frequency [4].

According to configuration of TV decors, there is no need to transmit sound to the outside the décor. So finding absorbing material with adequate frequency behavior has an important role in controlling sound inside decor. In this paper, we have investigated the influence of TV

\footnotetext{
${ }^{2}$ Bass ratio.

${ }^{3}$ Treble ratio.
} 
decors on acoustical conditions in the area.

\section{Designing of the Typical Studio and Simulation of Decors by ODEON Software}

At first, using ODEON software, a studio was designed in dimension of $16 \times 18$ and height of 10 meters and volume of 2880 cubic meters in order to put TV decors in a typical TV studio and check the changes in studio's reverberation time. In the case of volume, the reverberation time of studio in intermediate frequency according to the use of TV studio is 0.7 second [5]. 12 decors of different programs of IRIB channels were selected according to their form and structure and then simulated in the typical studio. In this simulation, all of the dimensions and angles totally correspond with the real decors dimensions (Figure 1). For taking into account the decors' surface diffusivity, scattering coefficient according to ODEON recommendations has been used. These coefficients are [6]:

Smooth surfaces 0.05;

Big surfaces 0.2;

Surfaces like book shelves 0.3 ;

Rough (uneven) surfaces 0.7 .

To calculate the reverberation time, the source and the receivers are located with the distance of $150 \mathrm{~cm}$ from the surface and each other and with the height of $120 \mathrm{~cm}$. Indeed, the reticulation of surface has done in $150 \mathrm{~cm}$ dimensions. The number of receivers in each décor is related to the span of that décor. The achieved figure for reverberation time based of iso3382 is the average number in frequency of 500 and $1000 \mathrm{~Hz}$. In the last column of the table1, the ratio of length of decor (L) to its depth (D) has put in centimeter scale that is indeed the length of apart sides. These decors have been made of chipboard, plywood and MDF as compound mixtures and there are glass, Polystyrene, and cloth structures inside of them. So they have not any major difference in terms of the material of used pages.

It should be pointed out that the materials used in different decors are similar and no other absorbing material has been used in their instruction. So it can be concluded that changes in RT are mainly due to decor's configurations and shapes. According to the mentioned descriptions, RT, BR, and TR are calculated in each décor and are given in Table $\mathbf{1}$.

\section{Analysis}

According to the amount of $\mathrm{JND}^{4}$ for reverberation time that is 5\% [7], checking above table shows that the changes of reverberation time by décors of programs named "Asra, Tolou, Simaye khanevadeh, and Hezar o yek shab", are in the range of JND and these changes

${ }^{4}$ Just noticeable difference. can't be perceived by the receiver. Indeed the planar decors of "Asra" and "Tolou" programs are dependent to the acoustic parameters of studio and cannot be used in non-standard acoustic environments. They don't function as improver of the acoustic conditions of ambiance but they can be used in standard studios confidently. Decors of "Simaye Khanevadeh" and "Hezar o yek shab" programs have these conditions too. Although these two decors are trihedral and have two apart sides, factors like low depth and high length caused that they follow the acoustic conditions of studio like planar decors (it should be mentioned that the glass surfaces in the décor of "Hezar o yek shab" are more than other decors and this issue can have some effects too).

Indeed the length of décor is higher than its depth and this implies that these structures have not any significant impact on the intermediate frequencies of sound waves. But if we have a more precise look at TR and BR, we can see that in décor of "Hezar o yek shab" program, higher frequencies have more constancy in the environment and therefore the sound has more sharpness in this setting.

This effect also appears in decor of Tolou program due to the reduction of BR. There is increase of BR and decrease of TR in décor of "Simaye Khanevadeh" which results in the increase of warmth of sound. In general, only in décor of "Simaye Khanevadeh" we see reduction of TR because of high scattering of frequencies caused with little bulges on the surfaces especially on the wall behind the sofas place. The rest of decors have increased the constancy of high frequencies in their environment, especially décors of "1446" and "Ordibehesht" which has the most increasing amount. In order to prevent the first contact of sound waves with the walls of studio and restricting the ambiance of moving of sound, the surfaces of décor decrease the absorption of air for high frequencies, but they have little effect on the low frequencies. So it's necessary to use high frequency absorbent materials in décor plates regularly, so that the slope of studio's RT curve is kept.

This is verified by looking at Table 2 (RT measurement values in real decors area). It should be pointed out that the difference in Tables $\mathbf{1}$ and 2 . Figures are due to the difference in the conditions of the real studio and the simulated one. The real studios are not in standard conditions and suffer from bad acoustical behavior, but the simulated one is a standard studio according to ODEON conditions, so these differences are predictable.

This compensates the amount of decrease in absorption of air in these frequencies in environment of décor in a uniform way and causes a more coordinated RT in all of the frequencies. This subject also is confirmed according to the table of practical measurement from decors (Table 2). According to the standards mentioned earlier, TR and BR figures are in the standard region, but 


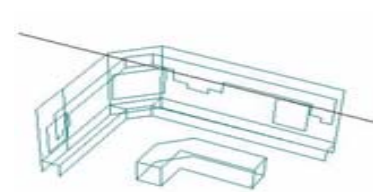

Asra

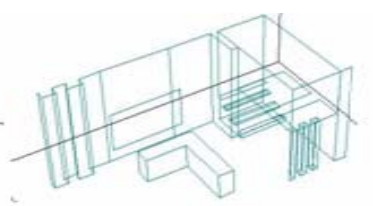

Tolou

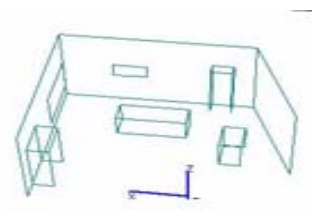

Doctor salam

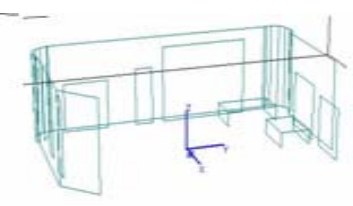

Khuneye zendegi

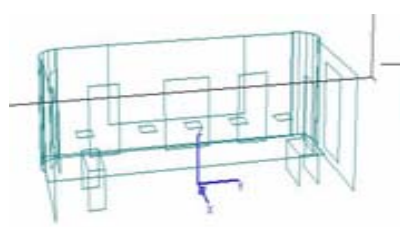

Roozazno

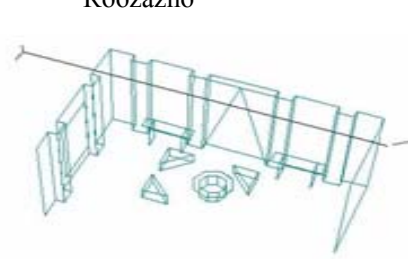

Ordibehesht

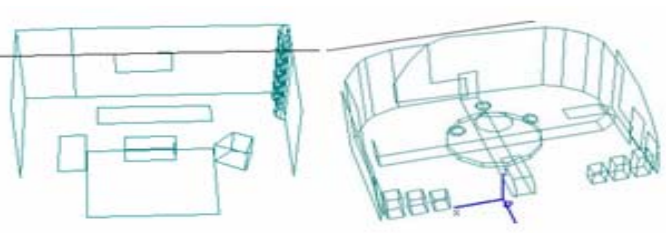

Sobhomid

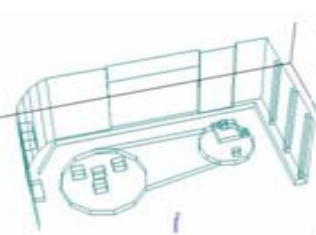

Hezaro yek shab
Aftab-e-sharghi

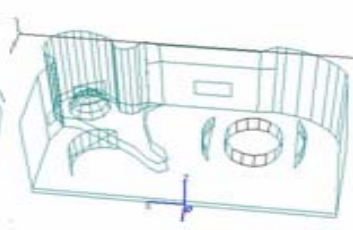

Jam-e-chahardahom

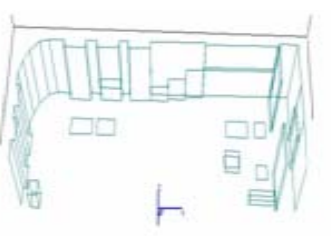

Simye khanevade

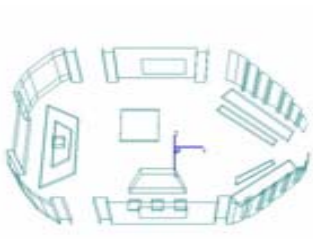

1446

Figure 1. 12 decors of different programs of IRIB channels, designed in typical TV studio simulation in ODEON.

Table 1. RT, BR, TR of the decor environment and changes percent RT of the decor environment to studio (numerical simulations).

\begin{tabular}{|c|c|c|c|c|c|}
\hline & RT (s) & Changes percent of studio RT & $\mathrm{BR}$ & TR & $\mathrm{L} / \mathrm{D}$ \\
\hline Studio & 0.75 & ----------- & 1.10 & 0.96 & ---- \\
\hline Doktor salam & 0.66 & $-12.00 \%$ & 1.10 & 0.98 & $480 / 300=1.60$ \\
\hline Khuneye Zendegi & 0.65 & $-13.33 \%$ & 1.10 & 0.98 & $1000 / 430=2.32$ \\
\hline Rooz az no & 0.64 & $-14.66 \%$ & 1.11 & 1.00 & $1000 / 430=2.32$ \\
\hline Sobhomid & 0.67 & $-10.66 \%$ & 1.15 & 1.00 & $700 / 340=2.05$ \\
\hline Asra & 0.69 & $-8.00 \%$ & 1.10 & 0.96 & ----------- \\
\hline Jam-e-chahardahom & 0.65 & $-13.33 \%$ & 1.11 & 0.96 & -------- \\
\hline Aftab-e-sharghi & 0.65 & $-13.33 \%$ & 1.09 & 0.99 & $700 / 390=1.79$ \\
\hline Simaye Khanevadeh & 0.71 & $-5.33 \%$ & 1.11 & 0.94 & $1500 / 540=2.77$ \\
\hline Tolou & 0.71 & $-5.33 \%$ & 1.05 & 0.97 & ------------- \\
\hline Ordibehesht & 0.67 & $-10.66 \%$ & 1.08 & 1.05 & $600 / 250=2.40$ \\
\hline Hezaro yek shab & 0.70 & $-6.66 \%$ & 1.05 & 1.01 & $1070 / 510=2.09$ \\
\hline 1446 & 0.65 & $-13.33 \%$ & 1.03 & 1.06 & ---------- \\
\hline
\end{tabular}

BR must not be lower than TR. Only in décor of "Jam-echahardahom" program the amount of TR is less than BR. This matter happens because of the use of high frequency absorbent materials such as carpet and polystyrene panels which rarely used in other decors. Indeed these decors almost cause to increase of the constancy of high frequencies in the environment of décor. The only décor that has prevented from this effect belongs to "Jam-echahardahom" program and this issue is confirmed in the table of practical measurement from decors (Table 2).

Decors of the programs named "Khuneye Zendegi" and "Rooz az no" have the same L/D but the amount of changes in reverberation time for "Rooz az no" program is more than the other one because it consists of chair, tables and plates made from cloth. This has the most effect on the studio's reverberation time and also causes the increase of TR.

Comparing the decors of programs "Aftab-e-Sharghi" and "1446", we can truly find the impact of décor's form to the reverberation time. Although the plates of décor in "1446" is much more than "Aftab-e-Sharghi" program (both has been made of plywood and chipboard). They 
Table 2. RT, BR, TR of practical measurement from the real decors environment, measured with SML B\&K2260.

\begin{tabular}{lccc}
\hline program & RT (S) & BR & TR \\
\hline Doktor salam & 0.74 & 0.85 & 0.93 \\
Khuneye Zendegi & 0.66 & 1.17 & 1.28 \\
Rooz az no & 0.68 & 1.15 & 1.25 \\
Sobhomid & 0.59 & 0.93 & 0.94 \\
Asra & 0.59 & 0.93 & 0.94 \\
Jam-e-chahardahom & 0.79 & 1.09 & 0.87 \\
Aftab-e-sharghi & 0.79 & 0.91 & 1.00 \\
Simaye Khanevadeh & 0.84 & 0.92 & 1.00 \\
Tolou & 0.99 & 1.04 & 1.03 \\
Ordibehesht & 1.01 & 1.00 & 1.01 \\
Hezaro yek shab & 1.01 & 1.00 & 1.00 \\
1446 & 1.10 & 0.92 & 0.99 \\
\hline
\end{tabular}

change the reverberation time of studio in a same scale and this change is absolutely perceptible by the receiver. The only reason of this event is the oval form of décor of "1446" that has increased the constancy of intermediate frequencies and reverberation time and also decreased the effect of sound absorption of its surfaces.

As was mentioned earlier there is no specific absorption in any décor rather than other decors, so the only reason of this effect have to be the extending shape and number of surfaces which have been used in 1446 décor in comparison to Aftab Sharqi. Décor of "Aftab-e-Sharghi" program having less surfaces, and with L/D lower than 2 which shows that depth and length of décor can be compared, has been able to control its inside setting better than other decors. Although the décor of "Rooz az no" has more effect on RT, "Aftab-e-Sharghi" program has less surfaces. Of course, in addition of appropriate length and depth, the structure of decors plates has a lot of importance too. In this décor the plates are not joint and are located in a way that there is 5 to $30 \mathrm{~cm}$ distance between the plates, and a part of each plate has been put behind the next plate in an arc form. Of course the presence of interior devices and structures in all spaces of décor has caused the scattering of sound and this issue has made an almost uniform reverberation environment. The picture below shows the profile surface of this décor (Figure 2).

Decor of "Jam-e-chahardahom" program has created this amount of reverberation time too. Regarding the presence of structures with more absorption coefficient (polystyrene structures, flooring from carpet and sofas made of leather), we can conclude that the reason of creation an effect like decor of "1446" is its semicircle form.

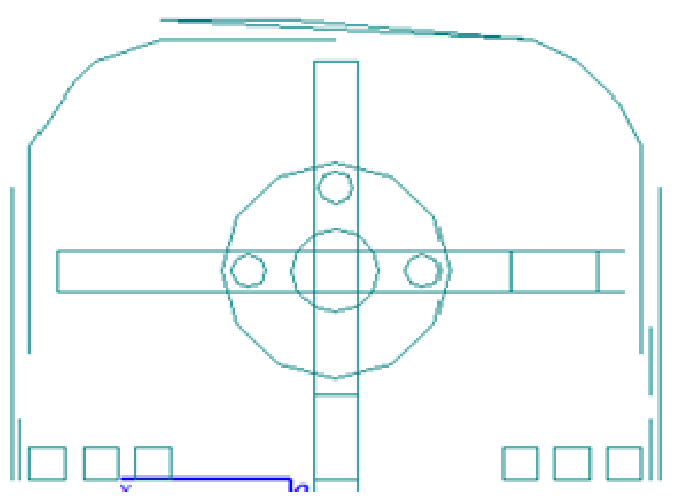

Figure 2. Top plane of Aftab-e-sharghi décor's.

\section{Conclusions}

1) Planar and trihedral decors with low depth and high length and less interior devices follow the acoustic conditions of ambiance and significantly are not able to acoustically control their interior environment.

2) Circular decors increase the reverberation time in intermediate frequencies because of creation of constancy of waves in environment.

3) Structures like décor of "Aftabe-Sharghi" program with less surfaces but depths proportional with the height of décor and the way of standing of décor's surfaces can have more effect on the reduction of RT in the ambiance.

Surfaces of décor cause to decrease of absorption of airborne in high frequencies due to restricting the environment. They also cause to increase of TR because of preventing from collision of waves to studio's absorbent surfaces in first echoes. In order to compensation of this effect, the use of high frequency absorbent materials and creation of bulges for scatter of these frequencies on the surfaces of décor is obligatory.

\section{REFERENCES}

[1] W. Siebein and Y. Kinzey, "Architectural-Acoustics," John Wiley \& Sons, Inc., New York, 1999, pp. 233-304.

[2] F. Alton Everest, "The Master Handbook of Acoustics," 4th Edition, Mc Graw Hill, New York, 2001

[3] R. S. Shankland, "Acoustical Designing for Performers," Journal of the Acoustical Society of America, Vol. 65, No. 1, 1979, pp. 140-144. doi:10.1121/1.382279

[4] E. Kahle and B. Katz, "Design of a New Stage Shell for the Stadthaus in Winterthur," 147th Meeting of the Acoustical Society of America, New York, 2004.

[5] L. Beranek, "Concert Halls and Opera Houses: Music, Acoustics, and Architecture," 2nd Edition, Springer-Verlag, New York, 2004.

[6] C. L. Christensen, "Odeon Room Acoustics Program Version 10," Scion DTU Diplomvej, Lyngby. http://www.odeon.dk.2010 
[7] F. Martellotta, "The Just Noticeable Difference of Center Time and Clarity Index in Large Reverberant Spaces,"
Acoustical Society of America. doi: $10.1121 / 1.3455837 .2010$ 